\title{
Analyses of Free Amino Acids in Different Parts of Bean Sprouts by Different Cooking Methods and from Different Merchants
}

\author{
Ji-Hye Kim, Kyung Ae Lee', Yong Ho Kim², and Hee-Seon Kim ${ }^{1 \dagger}$ \\ ${ }^{1}$ Department of Food Science and Nutrition, College of Natural Sciences and ${ }^{2}$ Department of Medicinal Biotechnology, \\ College of Medicinal Sciences, Soonchunhyang University, Chungnam 336-745, Korea
}

\begin{abstract}
This study was performed to quantitatively analyze free amino acids in the bean sprouts of three different merchants by the parts and the cooking methods in order to evaluate the nutritional and sensory values of bean sprouts. Three merchant bean sprouts were analyzed from total, cotyledon and hypocotyls. Aspartic acid was the most common acid isolated from bean sprouts from all three merchants and was found more in the hypocotyls than the cotyledon. On the other hand, arginine, the second most common amino acid, was found more in the cotyledon than the hypocotyls while valine, the third or fourth most common amino acid in total bean sprout, occumed in a greater amount in hypocotyls than in cotyledons. After cooking, was the most concentrated amino acid in the liquid portion of both boiled bean sprouts and bean sprout soup was glutamic acid. Total bean sprouts from merchant $C$ showed significantly higher contents of the most abundant amino acids, such as aspartic acid, arginine, alanine, senine, glutamic acid, isoleucine, leucine and tyrosine $(p<0.05)$. After cooking, bean sprouts from merchant $B$ showed less of a decrease in amino acid content in the solid parts than the products from merchants $A$ and $C$. In conclusion, aspartic acid was the major amino acid in bean sprouts, regardless of the source, but after cooking, glutamic acid became the most abundant amino acid in the liquid part. Additionally, the pattem of release of the amino acids from the solid beans to the liquid portion during cooking was different with each merchant.
\end{abstract}

Key words: bean sprout, free amino acids, amino acid analyzer, aspartic acid, soybean

\section{INTRODUCTION}

Bean sprouts are one of the most common of the traditional Korean foods, and they provide many nutritionally important components with relatively low price. The consumption of bean sprouts has been increasing since annual gross production of 650,000 tons in 1997 with industrial market value of 4000 billion Korean won (1). Currently annual gross production reaches up to about 480,000 tons (2). Along with Kimchi, bean sprouts are one of the most popular vegetables in Korea, and, in fact, rank the 3rd highest consumed vegetable among Koreans. It is well accepted that diet can affect health by various mechanisms. Dietary factors, including the essential nutrients abundant in bean sprouts, such as protein $(3,4)$, vitamin C (5), calcium (6), dietary fiber along with aspartic acid (7) and isoflavone (8) are attracting a lot of interest and increased consumption of bean sprouts is expected.

At this time, bean sprouts are sold for all purposes in Korea without any specification as to the type of sprout that is best suited for the different cooking pur- poses, such as making soup, cooked vegetables (namul), or making seasoned bean sprout dishes. In most cases, the quality of the bean sprout is often determined only by its outward appearance, without any objective and scientific quality control standards. The need to develop scientifically based, objective standards of determining the quality of a bean sprout and its best cooking use has been raised. Amino acid analyses are useful for establishing such standards since bean sprouts are a very good source of various amino acids. Many investigations (9-11) have been conducted to determine total amino acid content, although free amino acids in bean sprouts would be a greater contributor to flavor quality.

Therefore, this study analyzed the free amino acid content of bean sprouts in two different parts of the plant (cotyledon and hypocotyl) and from three different merchants. In addition to providing an evaluation of the nutritional values in different parts of bean sprouts, the results of this study provide baseline data for establishing standardized flavor components indices and a quality index. Koreans' most beloved bean sprout dishes were also analyzed to keep high standardized

${ }^{\dagger}$ Corresponding author. E-mail: hskim1@sch.ac.kr

Phone: +82-41-530-1263, Fax: +82-41-530-1264 
quality for boiled bean sprouts and bean sprout soup.

\section{MATERIALS AND METHODS}

\section{Materials}

Three different commercial brands of bean sprout manufactured on the same day of analyses were purchased from a local market in Asan. All three different merchants used Poongsan bean and bean sprouts from all three merchants were cultivated for 5 to 6 days at $20^{\circ} \mathrm{C}$. Purchased bean sprouts were washed with running tap water for 3 times and air-dried. The bean sprout was then separated into its components of cotyledon and hypocotyls with hair root. Three samples of bean sprouts from different merchants were washed, separated and freeze-dried, then analyzed as either total sprout, cotyledon or hypocotyl. The cooked bean sprouts were also analyzed after boiling for $3 \mathrm{~min}$ and the addition of ground green onion and garlic into the cooking water part. Boiled bean sprouts were prepared by putting 100 $\mathrm{g}$ bean sprout into $1 \mathrm{~L}$ of boiling water containing $0.4 \%$ salt and cooking for 3 min with a lid closed. After 3 min of cooking the solid parts were separated from the liquid part and the solid parts were washed promptly with cold water followed by air-drying. The solid parts were freeze-dried before analyses and the liquid parts were frozen and kept at $-20^{\circ} \mathrm{C}$ until analyses. Bean sprout soup was prepared by putting $100 \mathrm{~g}$ of bean sprouts into $750 \mathrm{~mL}$ of boiling water, along with $3 \mathrm{~g}$ of table salt, $1 / 2$ teaspoon of chopped garlic and 1/4 teaspoon of chop- ped green onion and boiling the soup with ingredients for 9 more min. After the additional boiling, the solid parts of the bean sprout soup were separated from the liquid part and the water was allowed to drip from the solid parts for $30 \mathrm{sec}$ on top of the sieved mesh. The solid parts were then freeze-dried and the liquid part of the soup was frozen at kept at $-20^{\circ} \mathrm{C}$ until the analyses.

\section{Analyses of free amino acids}

Half a gram of freeze-dried samples of each part were ground with mortar and pestle after $10 \mathrm{~mL}$ of $3 \%$ Trichloroacetic acid (TCA) solution was added. Ten $\mathrm{mL}$ of TCA solution and sea sand were added more as the sample was grounded and homogenized with vortex mixing. The homogenized sample was extracted with magnetic stirring bar at room temperature with lithium citrate buffer from freeze-dried bean sprouts after precipitate proteins with $3 \%$ trichloroacetic acid. After extraction, the sample was centrifuged at $15,000 \mathrm{rpm}$ for $15 \mathrm{~min}$ and the supernatant was collected. The supernatant was diluted with lithium citrate dilution buffer $(\mathrm{pH} 2.3)$ and made up to $50 \mathrm{~mL}$ and injected into the amino acid analyzer after filtering through $0.45 \mu \mathrm{m}$ syringe filter (2). Different dilution factors were applied depends on the sample parts.

The amino acid analyzer used was S7130, S5200, S2100 amino acid analyzer (Sykamm, Germany) and the columns used were cation separation column (LCA $\mathrm{K} 07 / \mathrm{Li} 4.6 \times 150 \mathrm{~mm}$, Sykamm, Germany), ammonia filtration column (LCA K05/Li 4.6×100 mm, Sykamm,

Table 1. Operating conditions and data acquisition parameters of amino acid analyzer for the analyses of bean sprouts

\begin{tabular}{|c|c|c|c|c|c|c|}
\hline \multicolumn{7}{|c|}{$\begin{array}{l}\text { Flow rate }- \text { Reactor } 0.25 \mathrm{~mL} / \mathrm{min} \\
\text { Pump } 0.45 \mathrm{~mL} / \mathrm{min}\end{array}$} \\
\hline \multicolumn{7}{|c|}{ Gas - Helium } \\
\hline \multicolumn{7}{|c|}{ Quaternary Delivery Pump S 2100 Gradient Program } \\
\hline Step & Time (min) & Flow $(\mathrm{mL} / \mathrm{min})$ & $\mathrm{A}^{1)}(\%)$ & $\mathrm{B}^{2)}(\%)$ & $\mathrm{C}^{3)}(\%)$ & $D^{4)}(\%)$ \\
\hline 0 & 0 & 0.45 & 100 & 0 & 0 & 0 \\
\hline 1 & 13.0 & 0.45 & 100 & 0 & 0 & 0 \\
\hline 2 & 1.0 & 0.45 & 79.0 & 21.0 & 0 & 0 \\
\hline 3 & 22.0 & 0.45 & 79.0 & 21.0 & 0 & 0 \\
\hline 4 & 11.0 & 0.45 & 52.0 & 48.0 & 0 & 0 \\
\hline 5 & 20.0 & 0.45 & 0 & 100 & 0 & 0 \\
\hline 6 & 5.0 & 0.45 & 0 & 0 & 100 & 0 \\
\hline 7 & 8.0 & 0.45 & 0 & 0 & 100 & 0 \\
\hline 8 & 4.0 & 0.45 & 0 & 0 & 78 & 88 \\
\hline 9 & 21.0 & 0.45 & 0 & 0 & 75 & 25 \\
\hline 10 & 0.1 & 0.45 & 0 & 0 & 0 & 100 \\
\hline 11 & 4.0 & 0.45 & 0 & 0 & 0 & 100 \\
\hline 12 & 0.1 & 0.45 & 100 & 0 & 0 & 0 \\
\hline 13 & 20.0 & 0.45 & 100 & 0 & 0 & 0 \\
\hline
\end{tabular}

${ }^{1)} \mathrm{A}$ : lithium citrate buffer A-1 $0.12 \mathrm{~N} ; \mathrm{pH} 2.90 .{ }^{2)} \mathrm{B}$ : lithium citrate buffer B-1 $0.30 \mathrm{~N} ; \mathrm{pH} 4.20 .{ }^{3)} \mathrm{C}$ : lithium citrate borate buffer $\mathrm{C}-40.30 \mathrm{~N}$; $\mathrm{pH} 8.0 .{ }^{4)} \mathrm{D}$ : regeneration solution $0.5 \mathrm{~N}$. 
Table 2. Free amino acid contents in the total bean sprouts by different merchants

\begin{tabular}{|c|c|c|c|}
\hline & A & B & $\mathrm{C}$ \\
\hline Aspartic acid & $241.8 \pm 4.3^{b}$ & $198.6 \pm 1.8^{\mathrm{c}}$ & $412.9 \pm 2.0^{\mathrm{a}}$ \\
\hline Arginine & $77.9 \pm 0.4^{\mathrm{b}}$ & $85.9 \pm 1.5^{\mathrm{a}}$ & $90.9 \pm 4.2^{\mathrm{a}}$ \\
\hline Alanine & $70.1 \pm 1.4^{\mathrm{c}}$ & $57.8 \pm 0.2^{\mathrm{b}}$ & $52.1 \pm 1.9^{\mathrm{a}}$ \\
\hline Valine & $61.8 \pm 1.4^{\mathrm{a}}$ & $43.8 \pm 0.8^{\mathrm{c}}$ & $52.1 \pm 0.1^{b}$ \\
\hline Histidine & $53.7 \pm 1.6^{\mathrm{a}}$ & $40.0 \pm 0.6^{\mathrm{b}}$ & $40.6 \pm 1.4^{b}$ \\
\hline Phenylalanine & $52.6 \pm 1.9$ & $43.5 \pm 0.8$ & $47.0 \pm 8.8$ \\
\hline Serine & $44.5 \pm 1.4^{\mathrm{b}}$ & $38.8 \pm 0.4^{\mathrm{c}}$ & $48.5 \pm 1.7^{\mathrm{a}}$ \\
\hline Glutamic acid & $29.4 \pm 9.9^{\mathrm{b}}$ & $32.2 \pm 7.4^{\mathrm{b}}$ & $58.0 \pm 3.3^{\mathrm{a}}$ \\
\hline Threonil & $39.1 \pm 1.2^{\mathrm{a}}$ & $29.1 \pm 0.9^{c}$ & $33.2 \pm 0.1^{\mathrm{b}}$ \\
\hline Isole & $37.5 \pm 1.2^{\mathrm{a}}$ & $27.3 \pm 1.1^{\mathrm{b}}$ & $36.6 \pm 0.0$ \\
\hline Leuci & $34.9 \pm 0.8^{\mathrm{b}}$ & $23.6 \pm 0.6^{\mathrm{c}}$ & $60.8 \pm 1.1^{\mathrm{a}}$ \\
\hline Tyrosine & $16.7 \pm 0$. & $9.6 \pm 0.2^{\mathrm{c}}$ & $24.7 \pm 2.2^{\mathrm{a}}$ \\
\hline Glycine & $15.4 \pm 0.3^{\mathrm{a}}$ & $13.6 \pm 0.2^{\mathrm{b}}$ & $9.6 \pm 0.7^{\circ}$ \\
\hline Tryptophan & $13.5 \pm 9.7$ & $25.1 \pm 9.6$ & $26.9 \pm 9.9$ \\
\hline Methionine & $5.1 \pm 0.1^{\mathrm{b}}$ & $4.3 \pm 0.2^{\mathrm{b}}$ & $9.6 \pm 1.3^{\mathrm{a}}$ \\
\hline Cystine & $1.9 \pm 0.1^{b}$ & $2.3 \pm 0.4^{b}$ & $6.7 \pm 0.8^{\mathrm{a}}$ \\
\hline
\end{tabular}

Means without a common superscript letter differs $(\mathrm{p}<0.05)$ with ANOVA and Tukey's post-hoc test.

Germany). Mobile phases were lithium citrate buffer $(0.25 \mathrm{~mL} / \mathrm{min})$ with different $\mathrm{pH}$ 's, and the flow rate of ninhydrin reagent was $0.5 \mathrm{~mL} / \mathrm{min}$ with injection volume of $100 \mu \mathrm{L}$. The temperature of the reactor was $130^{\circ} \mathrm{C}$, and the temperature of the column was $54 \sim$ $85^{\circ} \mathrm{C}$. All samples were analyzed in triplicate and the modified analysis condition (2) is described in Table 1.

The results of triplicates assays of the sprouts from the three different merchants were compared with ANOVA and a Tukey's post-hoc test.

\section{RESULTS}

The results of free amino acid analysis from total bean sprouts in different merchants were listed in Table 2. Free amino acid contents were also analyzed in the separate parts of bean sprouts (Tables 3 and 4) and compared by the different parts in Fig. 1. Although some amino acid levels differed from each merchant, aspartic acid was the most abundant amino acid in all three samples and arginine was the second most abundant amino acid. Aspartic acid was found most in both cotyledon and hypocotyls parts and arginine was found most in the cotyledon part while only small amounts were analyzed in the hypocotyls part of bean sprouts of three merchants. Except for the major two free amino acids, aspartic acid and arginine, valine, phenylalanine, serine and alanine were found in similar concentrations in the total sprout, although more of them were found in the hypocotyls regardless of the merchants; however, the order of concentration of each amino acid did differ by merchant. Merchant A showed significantly higher amount of as-
Table 3. Free amino acid contents in the cotyledon parts of bean sprouts by different merchants (dry basis, $\mathrm{mg} / 100 \mathrm{~g}$ )

\begin{tabular}{lrrr}
\hline & \multicolumn{1}{c}{$\mathrm{A}$} & \multicolumn{1}{c}{$\mathrm{B}$} & $\mathrm{C}$ \\
\hline Aspartic acid & $115.0 \pm 2.8^{\mathrm{c}}$ & $254.8 \pm 2.2^{\mathrm{b}}$ & $354.1 \pm 3.2^{\mathrm{a}}$ \\
Arginine & $94.9 \pm 1.5^{\mathrm{c}}$ & $109.4 \pm 6.3^{\mathrm{b}}$ & $153.0 \pm 5.8^{\mathrm{a}}$ \\
Glutamic acid & $37.2 \pm 6.3^{\mathrm{b}}$ & $35.9 \pm 6.4^{\mathrm{b}}$ & $64.9 \pm 5.5^{\mathrm{a}}$ \\
Phenylalanine & $26.1 \pm 0.7^{\mathrm{b}}$ & $35.5 \pm 5.1^{\mathrm{b}}$ & $46.9 \pm 5.4^{\mathrm{a}}$ \\
Serine & $26.5 \pm 0.1^{\mathrm{b}}$ & $28.5 \pm 1.5^{\mathrm{b}}$ & $44.8 \pm 8.5^{\mathrm{a}}$ \\
Histidine & $30.7 \pm 1.0^{\mathrm{b}}$ & $32.0 \pm 0.5^{\mathrm{b}}$ & $41.2 \pm 8.6^{\mathrm{a}}$ \\
Valine & $20.5 \pm 0.6^{\mathrm{b}}$ & $26.0 \pm 4.4^{\mathrm{b}}$ & $35.8 \pm 8.7^{\mathrm{a}}$ \\
Leucine & $22.3 \pm 0.6^{\mathrm{c}}$ & $27.1 \pm 2.4^{\mathrm{b}}$ & $34.2 \pm 1.9^{\mathrm{a}}$ \\
Isoleucine & $15.5 \pm 0.7$ & $21.1 \pm 4.8$ & $29.3 \pm 9.0$ \\
Alanine & $20.9 \pm 0.3$ & $22.8 \pm 2.3$ & $26.4 \pm 6.2$ \\
Threonine & $15.2 \pm 0.2$ & $19.1 \pm 3.1$ & $24.3 \pm 6.6$ \\
Tryptophan & $9.1 \pm 7.8^{\mathrm{b}}$ & $22.9 \pm 2.9^{\mathrm{a}}$ & $18.4 \pm 0.4^{\mathrm{b}}$ \\
Tyrosine & $11.2 \pm 0.0$ & $18.4 \pm 3.7$ & $21.8 \pm 6.7$ \\
Glycine & $7.2 \pm 0.2$ & $15.8 \pm 5.5$ & $10.8 \pm 3.9$ \\
Methionine & $4.1 \pm 0.3$ & $9.5 \pm 3.9$ & $8.4 \pm 4.3$ \\
Cystine & $3.1 \pm 0.3$ & $7.4 \pm 4.4$ & $7.0 \pm 3.9$ \\
\hline
\end{tabular}

Means without a common superscript letter differs $(\mathrm{p}<0.05)$ with ANOVA and Tukey's post-hoc test.

Table 4. Free amino acid contents in the hypocotyls parts of bean sprouts by different merchants (dry basis, mg/100 g)

\begin{tabular}{lrrr}
\hline & \multicolumn{1}{c}{$\mathrm{A}$} & \multicolumn{1}{c}{$\mathrm{B}$} & \multicolumn{1}{c}{$\mathrm{C}$} \\
\hline Aspartic acid & $343.1 \pm 2.0^{\mathrm{c}}$ & $346.9 \pm 2.8^{\mathrm{b}}$ & $531.3 \pm 2.6^{\mathrm{a}}$ \\
Alanine & $125.0 \pm 1.1^{\mathrm{b}}$ & $167.7 \pm 0.3^{\mathrm{a}}$ & $74.5 \pm 1.1^{\mathrm{c}}$ \\
Valine & $101.8 \pm 0.5^{\mathrm{c}}$ & $123.3 \pm 0.6^{\mathrm{a}}$ & $109.9 \pm 2.4^{\mathrm{b}}$ \\
Serine & $68.8 \pm 1.5^{\mathrm{b}}$ & $94.8 \pm 0.2^{\mathrm{a}}$ & $91.5 \pm 2.5^{\mathrm{a}}$ \\
Phenylalanine & $79.0 \pm 2.2^{\mathrm{b}}$ & $90.9 \pm 1.3^{\mathrm{a}}$ & $58.2 \pm 2.7^{\mathrm{c}}$ \\
Histidine & $69.6 \pm 1.7^{\mathrm{b}}$ & $77.4 \pm 0.9^{\mathrm{a}}$ & $43.6 \pm 1.5^{\mathrm{c}}$ \\
Threonine & $62.2 \pm 2.8^{\mathrm{b}}$ & $71.6 \pm 0.9^{\mathrm{a}}$ & $44.3 \pm 1.9^{\mathrm{c}}$ \\
Isoleucine & $59.2 \pm 2.6^{\mathrm{b}}$ & $68.4 \pm 1.3^{\mathrm{a}}$ & $45.0 \pm 1.2^{\mathrm{c}}$ \\
Glutamic acid & $12.8 \pm 1.0^{\mathrm{c}}$ & $27.7 \pm 1.1^{\mathrm{b}}$ & $54.4 \pm 8.7^{\mathrm{a}}$ \\
Leucine & $37.0 \pm 0.7^{\mathrm{a}}$ & $28.2 \pm 0.2^{\mathrm{b}}$ & $21.9 \pm 7.1^{\mathrm{b}}$ \\
Arginine & $22.9 \pm 0.1^{\mathrm{a}}$ & $6.3 \pm 0.1^{\mathrm{b}}$ & $6.3 \pm 0.3^{\mathrm{b}}$ \\
Tryptophan & $21.6 \pm 0.9^{\mathrm{a}}$ & $3.9 \pm 0.0^{\mathrm{c}}$ & $13.1 \pm 4.2^{\mathrm{b}}$ \\
Tyrosine & $14.2 \pm 0.1$ & $7.2 \pm 0.0$ & $16.9 \pm 8.3$ \\
Glycine & $10.0 \pm 9.9$ & $11.9 \pm 0.1$ & $6.1 \pm 1.2$ \\
Methionine & $2.0 \pm 1.8^{\mathrm{b}}$ & $2.9 \pm 0.1^{\mathrm{b}}$ & $8.0 \pm 2.3^{\mathrm{a}}$ \\
Cystine & $0.8 \pm 0.0^{\mathrm{a}}$ & $0.4 \pm 0.0^{\mathrm{b}}$ & $\mathrm{nd}^{1)}$ \\
\hline
\end{tabular}

${ }^{1)}$ nd: not detected.

Means without a common superscript letter differs $(\mathrm{p}<0.05)$ with ANOVA and Tukey's post-hoc test.

partic acid, arginine, alanine, serine, glutamic acid, isoleucine, leucine, tyrosine, methionine and cystine in the total bean, while contents of valine, histidine, threonine and glycine were significantly lower than the bean sprouts of the other merchants $(\mathrm{p}<0.05)$. Overall, merchant $\mathrm{C}$ showed more variations and different tendencies of amino acids distributions while merchants $\mathrm{A}$ and $\mathrm{B}$ showed the similar tendency of distribution in the total bean sprout. Results from the cotyledons were quite different from the results of the total bean especially for the amino acid with lower concentrations, such as isoleucine, alanine, threonine, tyrosine, glycine, methionine and cysteine. These amino acid contents were not sig- 
Fig. 1. Comparison of major free amino acid contents by different parts in bean sprouts of merchants A, B, and C.

nificantly different among the three merchants. Tryptophan content was significantly higher in the merchant $B(p<0.05)$ while other major amino acids such as aspartic acid, arginine, valine histidine, phenylalanine, serine and leucine were significantly higher in the cotyledon parts of merchant $C$. Aspartic acid content in the hypocotyls of merchant $\mathrm{C}$ was significantly higher than merchants $\mathrm{A}$ and $\mathrm{B}$ as the total and cotyledon parts, but alanine, valine, serine, phenylalanine, histidine, threonine and isoleucine were significantly higher in merchant $\mathrm{B}$ than in merchants $\mathrm{A}$ and $\mathrm{C}(\mathrm{p}<0.05)$. Other amino acids showed insignificant differences between the different merchants.

Table 5. Free amino acid contents in the liquid parts of the boiled bean sprouts and comparison by different merchants $(\mathrm{mg} / 100 \mathrm{~mL})$

\begin{tabular}{lrrr}
\hline & \multicolumn{1}{c}{$\mathrm{A}$} & \multicolumn{1}{c}{$\mathrm{B}$} & $\mathrm{C}$ \\
\hline Glutamic acid & $386.6 \pm 1.1^{\mathrm{a}}$ & $387.9 \pm 2.5^{\mathrm{a}}$ & $381.8 \pm 0.5^{\mathrm{b}}$ \\
Aspartic acid & $169.2 \pm 0.1^{\mathrm{b}}$ & $155.2 \pm 0.3^{\mathrm{c}}$ & $185.6 \pm 0.9^{\mathrm{a}}$ \\
Alanine & $53.4 \pm 0.6^{\mathrm{b}}$ & $53.9 \pm 0.3^{\mathrm{b}}$ & $57.5 \pm 0.6^{\mathrm{a}}$ \\
Serine & $36.5 \pm 0.1^{\mathrm{c}}$ & $37.8 \pm 0.3^{\mathrm{b}}$ & $44.1 \pm 0.3^{\mathrm{a}}$ \\
Valine & $40.4 \pm 1.1^{\mathrm{b}}$ & $41.6 \pm 1.2^{\mathrm{b}}$ & $43.5 \pm 1.0^{\mathrm{a}}$ \\
Arginine & $29.8 \pm 0.1^{\mathrm{c}}$ & $35.7 \pm 0.1^{\mathrm{a}}$ & $32.1 \pm 0.5^{\mathrm{b}}$ \\
Phenylalanine & $27.7 \pm 0.5^{\mathrm{b}}$ & $28.1 \pm 0.4^{\mathrm{b}}$ & $31.8 \pm 0.4^{\mathrm{a}}$ \\
Isoleucine & $24.1 \pm 0.1^{\mathrm{c}}$ & $26.1 \pm 0.5^{\mathrm{b}}$ & $27.9 \pm 0.2^{\mathrm{a}}$ \\
Threonine & $24.9 \pm 0.4^{\mathrm{b}}$ & $23.8 \pm 0.1^{\mathrm{c}}$ & $27.2 \pm 0.0^{\mathrm{a}}$ \\
Histidine & $25.2 \pm 0.4^{\mathrm{a}}$ & $23.5 \pm 0.2^{\mathrm{b}}$ & $25.5 \pm 0.3^{\mathrm{a}}$ \\
Leucine & $17.4 \pm 0.7^{\mathrm{c}}$ & $20.0 \pm 0.1^{\mathrm{b}}$ & $21.9 \pm 0.5^{\mathrm{a}}$ \\
Tyrosine & $10.1 \pm 2.2^{\mathrm{a}}$ & $8.0 \pm 0.4^{\mathrm{a}}$ & $11.3 \pm 0.6^{\mathrm{b}}$ \\
Glycine & $7.4 \pm 0.1^{\mathrm{a}}$ & $7.5 \pm 0.1^{\mathrm{a}}$ & $7.1 \pm 0.0^{\mathrm{b}}$ \\
Methionine & $1.6 \pm 0.1^{\mathrm{b}}$ & $1.7 \pm 0.0^{\mathrm{a}}$ & $1.5 \pm 0.1^{\mathrm{b}}$ \\
Tryptophan & $0.7 \pm 0.0^{\mathrm{a}}$ & $0.7 \pm 0.1^{\mathrm{a}}$ & $0.4 \pm 0.1^{\mathrm{b}}$ \\
Cystine & $0.7 \pm 0.0^{\mathrm{a}}$ & $0.5 \pm 0.0^{\mathrm{b}}$ & $0.5 \pm 0.0^{\mathrm{b}}$ \\
\hline
\end{tabular}

Means without a common superscript letter differs $(\mathrm{p}<0.05)$ with ANOVA and Tukey's post-hoc test.
The contents of free amino acids after boiling were also analyzed and the results are summarized in Tables 5 and 6 . The amounts of free amino acids released into the liquid portion of the boiled bean sprouts were similar in all three different merchants. Therefore, if bean sprouts were boiled for $3 \mathrm{~min}$, most amino acids stayed in the solid part and minor amounts were released into the boiling water. Kinds and contents of amino acids released into the boiling water varied dependent on the merchants, but amino acid released into the liquid part did not seem to be occur with any significance within 3 min of boiling. Sprouts from all three merchants released glutamic acid the most during boiling process.

Table 6. Free amino acid contents in the solid parts of the boiled bean sprouts and comparison by different merchants (dry basis, mg/100 g)

\begin{tabular}{lrrr}
\hline & \multicolumn{1}{c}{$\mathrm{A}$} & \multicolumn{1}{c}{$\mathrm{B}$} & \multicolumn{1}{c}{$\mathrm{C}$} \\
\hline Aspartic acid & $112.5 \pm 0.8^{\mathrm{c}}$ & $150.3 \pm 0.1^{\mathrm{b}}$ & $199.6 \pm 0.9^{\mathrm{a}}$ \\
Glutamic acid & $50.5 \pm 1.2^{\mathrm{a}}$ & $47.3 \pm 0.2^{\mathrm{b}}$ & $46.7 \pm 1.8^{\mathrm{b}}$ \\
Arginine & $49.3 \pm 7.6^{\mathrm{a}}$ & $33.0 \pm 0.0^{\mathrm{b}}$ & $37.6 \pm 0.8^{\mathrm{b}}$ \\
Alanine & $30.7 \pm 0.2^{\mathrm{c}}$ & $35.6 \pm 0.0^{\mathrm{b}}$ & $37.6 \pm 0.8^{\mathrm{a}}$ \\
Valine & $24.8 \pm 2.6^{\mathrm{b}}$ & $26.1 \pm 0.0^{\mathrm{b}}$ & $32.9 \pm 2.8^{\mathrm{a}}$ \\
Phenylalanine & $20.5 \pm 0.3^{\mathrm{b}}$ & $20.7 \pm 0.0^{\mathrm{b}}$ & $29.8 \pm 0.8^{\mathrm{a}}$ \\
Histidine & $21.9 \pm 0.2^{\mathrm{b}}$ & $26.5 \pm 0.0^{\mathrm{a}}$ & $26.9 \pm 0.8^{\mathrm{a}}$ \\
Serine & $19.8 \pm 0.2^{\mathrm{b}}$ & $23.3 \pm 0.0^{\mathrm{a}}$ & $20.4 \pm 0.6^{\mathrm{b}}$ \\
Threonine & $14.1 \pm 0.1^{\mathrm{c}}$ & $17.4 \pm 0.0^{\mathrm{a}}$ & $15.4 \pm 0.5^{\mathrm{b}}$ \\
Isoleucine & $15.6 \pm 0.2^{\mathrm{b}}$ & $16.5 \pm 0.0^{\mathrm{a}}$ & $15.2 \pm 0.4^{\mathrm{b}}$ \\
Leucine & $12.7 \pm 0.2^{\mathrm{a}}$ & $10.1 \pm 0.0^{\mathrm{b}}$ & $11.8 \pm 0.8^{\mathrm{a}}$ \\
Tryptophan & $11.3 \pm 0.1^{\mathrm{a}}$ & $11.4 \pm 0.1^{\mathrm{a}}$ & $10.0 \pm 0.5^{\mathrm{b}}$ \\
Tyrosine & $5.8 \pm 0.0^{\mathrm{b}}$ & $5.3 \pm 0.0^{\mathrm{c}}$ & $6.7 \pm 0.3^{\mathrm{a}}$ \\
Glycine & $5.2 \pm 0.1^{\mathrm{a}}$ & $3.9 \pm 0.0^{\mathrm{b}}$ & $4.1 \pm 0.2^{\mathrm{b}}$ \\
Methionine & $2.3 \pm 0.0^{\mathrm{a}}$ & $1.6 \pm 0.0^{\mathrm{b}}$ & $1.9 \pm 0.2^{\mathrm{b}}$ \\
Cystine & $0.3 \pm 0.1^{\mathrm{c}}$ & $3.2 \pm 0.0^{\mathrm{b}}$ & $4.3 \pm 0.3^{\mathrm{a}}$ \\
\hline
\end{tabular}

Means without a common superscript letter differs $(\mathrm{p}<0.05)$ with ANOVA and Tukey's post-hoc test. 
Table 7. Free amino acid contents in the liquid parts of the bean sprout soups and comparison by different merchants

\begin{tabular}{lccc} 
& & & $(\mathrm{mg} / 100 \mathrm{~mL})$ \\
\hline & $\mathrm{A}$ & $\mathrm{B}$ & $\mathrm{C}$ \\
\hline Glutamic acid & $494.9 \pm 1.6^{\mathrm{a}}$ & $454.1 \pm 4.7^{\mathrm{b}}$ & $454.5 \pm 1.6^{\mathrm{b}}$ \\
Aspartic acid & $327.1 \pm 7.3^{\mathrm{b}}$ & $331.9 \pm 2.8^{\mathrm{b}}$ & $382.9 \pm 1.5^{\mathrm{a}}$ \\
Arginine & $208.6 \pm 2.4^{\mathrm{a}}$ & $198.4 \pm 1.5^{\mathrm{b}}$ & $208.7 \pm 3.4^{\mathrm{a}}$ \\
Alanine & $106.5 \pm 0.1^{\mathrm{b}}$ & $108.0 \pm 0.4^{\mathrm{b}}$ & $114.4 \pm 1.7^{\mathrm{a}}$ \\
Serine & $81.3 \pm 1.0^{\mathrm{c}}$ & $86.5 \pm 0.4^{\mathrm{b}}$ & $103.6 \pm 0.1^{\mathrm{a}}$ \\
Valine & $86.8 \pm 1.0^{\mathrm{c}}$ & $90.7 \pm 0.8^{\mathrm{b}}$ & $100.0 \pm 0.0^{\mathrm{a}}$ \\
Phenylalanine & $660 \pm 0.0^{\mathrm{c}}$ & $70.4 \pm 0.2^{\mathrm{b}}$ & $77.1 \pm 0.2^{\mathrm{a}}$ \\
Histidine & $60.8 \pm 2.2^{\mathrm{b}}$ & $62.7 \pm 0.2^{\mathrm{b}}$ & $68.7 \pm 1.5^{\mathrm{a}}$ \\
Isoleucine & $55.7 \pm 0.4^{\mathrm{c}}$ & $62.6 \pm 0.1^{\mathrm{b}}$ & $66.7 \pm 1.0^{\mathrm{a}}$ \\
Threonine & $53.2 \pm 0.3^{\mathrm{b}}$ & $49.6 \pm 0.1^{\mathrm{c}}$ & $58.6 \pm 0.8^{\mathrm{a}}$ \\
Leucine & $44.6 \pm 0.2^{\mathrm{c}}$ & $55.4 \pm 1.5^{\mathrm{a}}$ & $51.4 \pm 0.3^{\mathrm{b}}$ \\
Tyrosine & $26.0 \pm 0.1^{\mathrm{b}}$ & $26.6 \pm 2.1$ & $26.2 \pm 1.4$ \\
Glycine & $16.4 \pm 0.1^{\mathrm{b}}$ & $18.3 \pm 0.2^{\mathrm{a}}$ & $15.7 \pm 0.0^{\mathrm{c}}$ \\
Methionine & $5.0 \pm 0.2^{\mathrm{b}}$ & $5.4 \pm 0.1^{\mathrm{a}}$ & $4.7 \pm 0.0^{\mathrm{b}}$ \\
Tryptophan & $2.6 \pm 0.2^{\mathrm{a}}$ & $2.7 \pm 0.1$ & $2.7 \pm 0.1$ \\
Cystine & $2.0 \pm 0.1^{\mathrm{a}}$ & $1.8 \pm 0.0^{\mathrm{b}}$ & $1.5 \pm 0.2^{\mathrm{b}}$ \\
\hline Means without & &
\end{tabular}

Means without a common superscript letter differs $(\mathrm{p}<0.05)$ with ANOVA and Tukey's post-hoc test.

Table 8. Free amino acid contents in the solid parts of the bean sprout soups and comparison by different merchants

\begin{tabular}{lrrr} 
& & \multicolumn{2}{c}{ (dry basis, mg/100 g) } \\
\hline & $\mathrm{A}$ & $\mathrm{B}$ & $\mathrm{C}$ \\
\hline Aspartic acid & $186.8 \pm 2.0^{\mathrm{c}}$ & $267.0 \pm 1.2^{\mathrm{a}}$ & $195.8 \pm 2.2^{\mathrm{b}}$ \\
Glutamic acid & $59.4 \pm 0.2^{\mathrm{c}}$ & $85.0 \pm 0.4^{\mathrm{a}}$ & $68.6 \pm 0.6^{\mathrm{b}}$ \\
Arginine & $46.4 \pm 0.6^{\mathrm{b}}$ & $49.7 \pm 0.2^{\mathrm{a}}$ & $49.1 \pm 0.2^{\mathrm{a}}$ \\
Alanine & $17.7 \pm 0.4^{\mathrm{b}}$ & $29.4 \pm 0.7^{\mathrm{a}}$ & $30.0 \pm 0.2^{\mathrm{a}}$ \\
Serine & $20.8 \pm 0.2^{\mathrm{c}}$ & $29.5 \pm 0.0^{\mathrm{a}}$ & $25.4 \pm 0.4^{\mathrm{b}}$ \\
Valine & $18.2 \pm 0.2^{\mathrm{c}}$ & $27.6 \pm 0.1^{\mathrm{a}}$ & $21.8 \pm 0.3^{\mathrm{b}}$ \\
Threonine & $12.9 \pm 0.7^{\mathrm{c}}$ & $26.1 \pm 0.5^{\mathrm{a}}$ & $23.3 \pm 0.3^{\mathrm{b}}$ \\
Histidine & $19.5 \pm 0.9^{\mathrm{b}}$ & $22.4 \pm 0.2^{\mathrm{a}}$ & $19.4 \pm 0.2^{\mathrm{b}}$ \\
Phenylalanine & $16.4 \pm 0.5^{\mathrm{c}}$ & $22.4 \pm 0.2^{\mathrm{a}}$ & $19.5 \pm 0.2^{\mathrm{b}}$ \\
Isoleucine & $13.9 \pm 0.2^{\mathrm{c}}$ & $18.7 \pm 0.3^{\mathrm{a}}$ & $15.5 \pm 0.1^{\mathrm{b}}$ \\
Tyrosine & $8.8 \pm 0.2^{\mathrm{c}}$ & $13.3 \pm 0.2^{\mathrm{a}}$ & $14.8 \pm 0.2^{\mathrm{a}}$ \\
Leucine & $9.9 \pm 0.3^{\mathrm{c}}$ & $14.0 \pm 0.2^{\mathrm{a}}$ & $13.1 \pm 0.1^{\mathrm{b}}$ \\
Tryptophan & $11.2 \pm 0.6$ & $11.6 \pm 0.5$ & $10.4 \pm 0.7$ \\
Glycine & $3.0 \pm 0.2^{\mathrm{b}}$ & $7.5 \pm 0.1^{\mathrm{a}}$ & $7.2 \pm 0.2^{\mathrm{a}}$ \\
Methionine & $\mathrm{nd}^{1)}$ & $6.7 \pm 0.2^{\mathrm{b}}$ & $7.3 \pm 0.1^{\mathrm{a}}$ \\
Cystine & $\mathrm{nd}$ & $2.7 \pm 0.4$ & $2.4 \pm 0.2^{2}$ \\
\hline
\end{tabular}

${ }^{1)}$ nd: not detected.

Means without a common superscript letter differs $(\mathrm{p}<0.05)$ with ANOVA and Tukey's post-hoc test.

On the other hand, aspartic acid, the most abundant amino acid in bean sprouts, released the least from merchant $\mathrm{B}$, although the original contents of aspartic acid in total bean sprout parts of merchant $\mathrm{B}$ was significantly lower than the other merchants $(\mathrm{p}<0.05)$.

When the bean sprout was cooked as soup, free amino acid contents in both liquid and solid parts were analyzed and shown in Tables 7 and 8. Bean sprout soup was cooked longer than the boiled bean sprout and seasonings such as some green onions and garlic were added. Therefore the results of free amino acid contents in the
Fig. 2. Comparison of major free amino acid contents by different cooking methods in bean sprouts of merchants $\mathrm{A}, \mathrm{B}$, and $\mathrm{C}$.

liquid and solid parts of bean sprout soup were different from the boiled bean sprouts. Moreover, more amino acids were analyzed in the liquid part of the soup for 9 min of cooking compared to the boiled water after three min of boiling (Fig. 2). However, similar amounts of free amino acids were analyzed in the solid parts when cooked both as soup and boiling was applied as a cooking method. More cooking time and added seasonings would contribute more free amino acids contents in the liquid parts of the soup compared with 3 min of boiling water. 


\section{DISCUSSION}

Free amino acid content analyses were conducted on bean sprouts (total sprout and the cotyledon and hypocotyls components) from three different merchants to acquire baseline data for establishing standardized flavor component indices and a quality index. The order of the free amino acid concentrations in total sprouts were, from greatest to least, aspartic acid, arginine, alanine, valine, phenylalanine, histidine, serine, glutamic acid, isoleucine, threonine, leucine, tyrosine, tryptophane, glycine, methionine and cystine. However, amino acids other than the six mentioned in the results section as being the most common showed varying concentrations, depending on the different merchants. This discrepancy observed among the different merchants was more distinct when the concentrations of the amino acids were compared by the different parts of bean sprouts, and could be attributable to the different cultivating methods of each merchants, although all three merchants used the same kind of bean (Poongnam). Unfortunately, it was not possible to get specific information on the growing methods used by each merchant. The only information available was the cultivation dates. Many investigators (12-16) reported that different bean species used for bean sprout show different quality levels, sprouting conditions, growth characteristics and physiological changes. Therefore, the main contributor to the free amino acid content of bean sprout is the bean seed used for the sprouting, even with the same Poongnam bean; however, when and where to harvest would be other factors that contribute to the differences. A follow-up study will analyze and compare the free amino acids content according to the different bean seed species used for sprouting.

For the present study, we freeze-dried the samples before analyses and the contents of free amino acids were expressed as $\mathrm{mg} \%$. The results of the present study showed somewhat higher free amino acid contents compared to the other studies reported to date $(2,10,11$, 16-18). Since the purpose of the present study is to analyze free amino acids contents from the different bean sprout merchants and compare them after different cooking methods, we chose to freeze-dry the samples for the consistency and convenience of storage before the pretreatment of all samples. Thus, the higher contents analyzed in the present study than the previously reported studies were likely due to the different samples, analyses methods and pretreatment methods used. Usually, amino acids analyses were conducted after acid digestion, which releases amino acids. During the processes of acid elimination and concentration that take place before injection of samples into the analyzer, some amino acid loss is expected. We chose to analyze free amino acid content rather than total amino acids, since our purpose was to identify the factors affecting flavor components indices and quality indexes, which are better explained by free amino acids (19).

When the amino acids contents were analyzed after boiling for $3 \mathrm{~min}$, some amino acids contents observed in the solid parts were lower than the contents from the total part. Glutamic acid was the most possibly released amino acids from the solid parts out of free amino acids analyzed, although amounts of glutamic acid found in boiling water were different by the merchants. Overall, merchant B showed the least release from the solid parts after 3 min of boiling although the original amino acid contents before cooking were less in the merchant B than the other two merchants. When bean sprout soup was cooked, more amino acids were analyzed in the liquid parts of the soup. Free amino acid contents in the liquid portion of the soup are expected be higher than in plain boiling water because soup making requires a longer cooking time $(9 \mathrm{~min})$ and some seasonings were added. Both liquid and solid parts of soup are consumed, and the relatively higher concentration of free amino acids found in the liquid part of the soup is not considered to be nutrients losses.

Nutritional values of beans while in the seed stage and their beneficial health effects, as well as their nutritional values, are well documented (20-25). During the sprouting process of bean seeds, lipid contents diminish while protein, vitamins $\mathrm{A}$ and $\mathrm{C}$ and fiber contents increase, and carbohydrates transform into more easily digested monosaccharides $(26,27)$. Therefore, more research is being proposed for developing the second generation bean products in the US and the western European countries, where the consumption of bean products is much lower than in the Asian countries (28-31). A more specific and systemized research focused on bean and bean sprout products are also essential and urgent in Korea, as well as other Asian countries. Asians have consumed bean products for a long time without fully investigating their many nutritional benefits. The present study focused on providing the basal data of bean sprouts to help develope standardized flavor indices and nutritional values for the expected increase of bean product consumption. In conclusion, we found that aspartic acid is the most abundant amino acid in all parts of bean sprout, regardless of the source. Aspartic acid concentration was higher in the hypocotyl than in the cotyledon. The next most common amino acid was arginine, which was found more in the cotyledon than in the hypocotyls while the third most abundant free amino acid was valine, which was found more in 
the hypocotyls than in the cotyledon part. Glutamic acid is the amino acid released most from the solid parts into the liquid part while cooking, either boiling plain or making soup, regardless of the merchant. Sprouts from merchant B showed the least amount of glutamic acid release while cooking, although the original aspartic acid contents were less than those of merchants $\mathrm{A}$ and $\mathrm{C}$. Differences found from the different merchants might be attributable to the different methods used for sprouting, even if all three merchants used Poongnam bean. Therefore, follow-up studies are underway to compare free amino acid contents of different soybean seeds cultivated under identical methods.

\section{ACKNOWLEDGEMENT}

This study was supported by the grants from Rural Development Administration (Project 200803A01080067).

\section{REFERENCES}

1. Lee YS, Kim YH. 2005. Characterization of postharvest related to quality on soybean sprout. Soonchunhyang $J$ Natural Sci 11: 55-62.

2. Park IK, Kim SD. 2003. Sugar and free amino acid content of chitosan-treated soybean sprout. J Chitin Chitosan 8: 105-116.

3. Choi HD, Kim SS, Hong HD, Lee JY. 2000. Comparison of physicochemical and sensory characteristics of soybean sprouts from different cultivars. J Korean Soc Agric Chem Biotechnol 43: 207-212.

4. Yang CB. 1982. Changes of nitrogen compounds and nutritional evaluation of soybean sprout. Part V. Relationship among trypsin inhibitor activity, digestibility and nutritional value. J Korean Agric Chem Soc 25: 8-13.

5. Kim SD, Jang BH, Kim HS, Ha KH, Kang KS, Kim DH. 1982. Studies on the changes in chlorophyll, free amino acid and vitamin $\mathrm{C}$ content of soybean sprouts during circulation periods. Korean J Nutr Food 11: 57-62.

6. Abdullah A, Ruth EB. 1984. Mineral and vitamin contents of seeds and sprouts of newly available small-seeded soybeans and market samples of mungbeans. J Food Sci 49: 656-657.

7. Byun SM, Huh NE, Lee CY. 1997. Asparagine biosynthesis in soybean sprouts. J Korean Agric Chem Soc 20: 33-42.

8. Kim EM, Lee KJ, Chee KM. 2004. Comparison in isoflavone contents between soybean and soybean sprouts of various soybean cultivars. Korean J Nutr 37: 45-51.

9. Plaza L, de Ancos B, Cano MP. 2003. Nutritional and health-related compounds in sprouts and seeds of soybean (Glycine max), wheat (Triticum aestivum. L) and alfalfa (Medicago sativa) treated by a new drying method. Eur Food Res Technol 216: 138-144.

10. Yang CB. 1981. Changes of nitrogen compounds and nutritional evaluation of soybean sprout. Part III. Changes of free amino acid composition. J Korean Agric Chem Soc 24: 101-104.

11. Xu MJ, Dong JF, Zhu MY. 2005. Effects of germination conditions on ascorbic acid level and yield of soybean sprouts. J Sci Food Agric 85: 943-947.

12. Jeon SH, Lee CW, Kim KY, Kim HK, Kang JH. 2008. Growth of soybean sprouts affected by period and method of seed storage. Korean J Crop Sci 53: 21-27.

13. Kim EJ, Lee KI, Park KY. 2002. Effects of germination treatment during cultivation of soybean sprout. $J$ Korean Soc Food Sci Nutr 31: 615-620.

14. Kim KH. 1992. The growth characteristics and proximate composition of soybean sprouts. Korean Soybean Digest 9: $27-30$

15. Shin DH, Choi U. 1996. Comparison of growth characteristics of soy bean sprouts cultivated by three methods. Korean J Food Sci Technol 28: 240-245.

16. Song J, Kim SL, Hwang JJ, Son YK, Song JC, Hur HS. 2000. Physicochemical properties of soybean sprouts according to culture period. Korean Soybean Digest 17: 84-89.

17. Korea Health Industry Development Institute. 2004. Development of nutrient database IV: amino acid composition of foods. Korea Health Industry Development Institute. Seoul, Korea.

18. Kim IS, Choi SY, Chung MJ, Kim TH, Sung NJ. 2005. Effect of ion chip and yellow soil on growth and physicochemical characteristics of soybean sprouts. Korean $J$ Food Nutr 18: 316-324.

19. National Institute of Crop Science. 2004. Available component analysis and evaluation in crops. National Institute of Crop Science. Seoul, Korea.

20. Anderson JW, Johnstone BM, Cook-Newell ME. 1995. Metaanalysis of the effect of soy protein intake on serum lipid. New Eng J Med 333: 276-282.

21. Gallagher JC, Raffererty K, Hayanazka V, Wilson W. 2000. The effect of soy: protein on bone metabolism. $J$ Nutr 130: 667S-673S.

22. Kennedy AR. 1995. The evidence of soybean products as cancer preventive agents. J Nutr 125: 733S-743S.

23. Messina M. 1999. Legumes and soybeans: overview of their nutritional profiles and health effects. Am J Clin Nutr 70: 439S-450S.

24. Messina M. 2001. Noteworthy evidence mounts on soy and human health. J Am Diet Assoc 9: 1-3.

25. Trock B, Butler LW, Clarke R, Hilakivi-Clarke L. 2000. Meta analysis of soybean sprouts according to culture period. Korean Soybean Digest 17: 84-89.

26. Collins JL, Sand GG. 1976. Changes in trypsin inhibitory activity of Korean soybean varieties during maturation and germination. J Food Sci 41: 168-172.

27. Kim SD, Kim SH, Hong EH. 1993. Composition of soybean sprouts and its nutritional value. Korean Soybean Digest 6: 1-9.

28. Drake MA, Chen XO, Tamarapu S, Leenanon B. 2000 Soy protein fortification affect sensory, chemical and microbiological properties of dairy yoghurts. J Food Sci 65 : 1244-1247.

29. Friedeck KG, Karagul-Yuceer Y, Drake MA. 2003. Soy protein fortification of a low-fat dairy-based ice cream. J Food Sci 66: 2651-2657.

30. Lee SY, Morr CV, Seo A. 1990. Comparison of milk-based and soy milk-based yoghurt. J Food Sci 55: 532-536.

31. McIssac C, Potter SM, Weigel MM. 1993. Effect of consumer education on the purchase of soy-containing bakery item. Cereal Food Worlds 38: 154-156.

(Received July 23, 2009; Accepted October 21, 2009) 